\title{
Continuous peripheral nerve blocks for postoperative analgesia in children: feasibility and side effects in a cohort study of $\mathbf{3 3 9}$ catheters
}

\section{Blocs nerveux périphériques continus pour l'analgésie postopératoire chez l'enfant: efficacité et effets secondaires dans une cohorte de 339 cathéters}

\author{
Christophe Dadure, MD · Sophie Bringuier, PhD • Olivier Raux, MD · \\ Alain Rochette, MD - Rachel Troncin, MD - Nancy Canaud, MD • \\ Jean-François Lubrano-Lavadera, MD · Xavier Capdevila, MD, PhD
}

Received: 11 June 2009/Accepted: 6 August 2009/Published online: 21 August 2009

(c) Canadian Anesthesiologists' Society 2009

\begin{abstract}
Introduction Perioperative continuous peripheral nerve blocks (CPNB) are increasingly being used in children. Only one previous study has reported adverse events of $C P N B$ in a high number of pediatric cases. We evaluated the indications, block efficacy, and adverse events related to $C P N B$ in children.

Methods All CPNBs that were performed in children for postoperative analgesia over a 5-year period at the Montpellier University Hospital in France were included in this study. The first bolus dose and the continuous doses of local anesthetic were not standardized. In the postoperative period, demographic data, quality of analgesia, amount of rescue analgesic medication, child/parent satisfaction, and adverse events were recorded in our Departmental Regional Anesthesia registry.
\end{abstract}

Results A total of 339 catheters were evaluated in 292 children ASA physical status I to III. The median age was

C. Dadure, MD · S. Bringuier, PhD · O. Raux, MD .

A. Rochette, MD · R. Troncin, MD · N. Canaud, MD .

J.-F. Lubrano-Lavadera, MD · X. Capdevila, MD, PhD

Department of Anesthesia and Critical Care Medicine,

Lapeyronie University Hospital, Montpellier, France

S. Bringuier, $\mathrm{PhD}$

Department of Biostatistics, Lapeyronie University Hospital,

Montpellier, France

C. Dadure, MD ( $\square)$

Service d'Anesthésie Réanimation A, Hôpital Lapeyronie,

371 Avenue du Doyen G. Giraud, 34295 Montpellier, France

e-mail: c-dadure@chu-montpellier.fr
8 yr (0.6-17 yr) and the median weight was $28 \mathrm{~kg}$ (7$116 \mathrm{~kg})$. The main surgical indications were hip, femoral, or tibial osteotomies (44.5\%) and club foot repair (27.4\%). The local anesthetics used were either bupivacaine or ropivacaine. The mean volume of the local anesthetic bolus dose was $0.49 \pm 0.16 \mathrm{~mL} \cdot \mathrm{kg}^{-1}$, and the mean regimen of local anesthetic continuous infusion was $0.11 \pm 0.04 \mathrm{~mL} \cdot \mathrm{kg}^{-1}$. $\mathrm{hr}^{-1}$. The median duration of CPNB was $61.6 \mathrm{hr}$ (range 0-264 hr). Pain relief, which was evaluated with the children at rest, was considered optimal in the majority of patients throughout the study period. The Children and Infants Postoperative Pain Scale (CHIPPS) was used in children age 0-6 yr and the Visual Analog Pain Scale (VAS) was used in children 7 yr and older. There were no major adverse events. There were 211 minor adverse events recorded in 153 CPNBs (45.1\%). The most frequently reported complication $(20.1 \%)$ involved mechanical problems with the catheter, followed by nausea and vomiting (14.7\%).

Conclusion CPNBs are indicated after orthopedic surgery in children. Our results demonstrate that CPNBs are feasible in the pediatric setting, and in skilled hands, they promote prolonged analgesia in the majority of patients without major adverse events. The most common minor adverse events are catheter-related mechanical problems and postoperative nausea and vomiting.

\section{Résumé}

Introduction Les blocs nerveux périphériques continus (BNPC) sont de plus en plus utilisés chez l'enfant. À ce 
jour, une seule étude a rapporté les effets indésirables d'un grand nombre de cas pédiatriques. Nous avons évalué les indications, l'efficacité des blocs et les effets indésirables liés aux BNPC chez l'enfant.

Méthode Tous les BNPC réalisés chez des enfants pour l'analgésie postopératoire sur une période de 5 ans à l'hôpital universitaire de Montpellier, en France, ont été inclus dans cette étude. La réalisation du bloc, la dose du bolus d'induction et du mode continu n'étaient pas standardisées. Dans la période postopératoire, les données démographiques, la qualité de l'analgésie, les demandes d'analgésiques de secours, la satisfaction des parents et des enfants et les effets indésirables ont été enregistrés dans la base de données d'anesthésie locorégionale de notre département.

Résultats Un total de 339 cathéters chez 292 enfants, de grade ASA 1 à 3, ont été évalués. La médiane d'âge était de 8 (0,6-17) ans, et la médiane de poids était de 28 (7-116) $\mathrm{kg}$. Les principales indications chirurgicales étaient les ostéotomies de hanche, de fémur ou de tibia (44,5\%) et les chirurgies de pied bot (27,4\%). Les anesthésiques locaux utilisés étaient de la bupivacaïne ou de la ropivacaïne. Le volume moyen de la dose d'induction était de 0,49 \pm $0,16 \mathrm{~mL} \cdot \mathrm{kg}^{-1}$, et la dose moyenne du débit continu était de $0,11 \pm 0,04 \mathrm{~mL} \cdot \mathrm{kg}^{-1} \cdot \mathrm{h}^{-1}$. La durée moyenne du BNPC était de 61,6 (0-264) heures. Le soulagement de la douleur, évaluée au repos par le score de CHIPPS pour les enfants de moins de 7 ans et par le score d'EVA pour les enfants de plus de 7 ans, était optimal pour la majorité des patients durant la période étudiée. Il n'y a pas eu d'effets indésirables graves. Il y a eu 211 effets indésirables mineurs enregistrés chez 153 cathéters $(45,1 \%)$. Les problèmes mécaniques avec les cathéters étaient les plus fréquemment rapportés $(20,1 \%)$, suivis par les nausées et vomissements $(14,7 \%)$.

Conclusion Les BNPC sont indiqués pour la chirurgie orthopédique chez l'enfant. Nos résultats démontrent que les $B N P C$ sont des techniques réalisables chez une population pédiatrique et permettent une analgésie prolongée chez la majorité des patients sans effet indésirable grave pour des praticiens expérimentés. Les effets indésirables mineurs les plus fréquents sont des problèmes techniques liés aux cathéters et les nausées et vomissements postopératoires.

Peripheral nerve blocks (PNBs) are widely used in adult orthopedic patients. Nowadays, PNBs are increasingly being used in children. Giaufre et al. ${ }^{1}$ demonstrated the safety and efficiency of regional anesthesia techniques in a prospective survey over a 1-year period. No complications were observed among 4,090 peripheral nerve blocks compared with a $0.15 \%$ incidence of complications with caudal blocks. In 2007, these techniques were in regular use by pediatric anesthesiologists when appropriate for postoperative pain management. ${ }^{2}$

The main concern regarding single shot nerve blocks, even with adjuvant, is the limited duration of analgesia. ${ }^{3}$ Consequently, single shot blocks have not been widely adopted for major pediatric orthopedic surgery. In a limited number of patients, continuous peripheral nerve block (CPNB) has been reported to allow complete and prolonged postoperative pain relief in children. ${ }^{4-6}$ CPNBs are associated with fewer side effects after lower limb surgery in children compared with continuous epidural blocks. ${ }^{5}$ However, only one trial has been published with a high number of pediatric cases. ${ }^{6}$ Moreover, it has recently been reported that CPNB carries a low rate of complications in adult orthopedic patients, and major neurological and infectious adverse events are rare. ${ }^{7,8}$ The incidence of these complications in children is unknown. In this retrospective review of consecutively collected data, we evaluated the feasibility of CPNB in children undergoing orthopedic surgical procedures. The primary outcome was the efficiency of the CPNBs in terms of prolonged postoperative analgesia. We also evaluated the different side effects related to CPNB in children.

\section{Methods}

This study was approved by the Commission Nationale de l'Informatique et des Libertés (French National Information Review Board), and parental informed consent was obtained for all patients for registry of previously withheld data.

All children were enrolled who were ASA status I-III, age 1-17 yr, and scheduled for CPNB after major orthopedic surgery at the Montpellier University Hospital, France from January 2002 to December 2006. Data for all children who received CPNB were collected contemporaneously and entered into our Department Regional Anesthesia registry.

All patients were premedicated using midazolam $0.4 \mathrm{mg} \cdot \mathrm{kg}^{-1}$ and atropine $20 \mu \mathrm{g} \cdot \mathrm{kg}^{-1}$ rectally or hydroxyzine $1 \mathrm{mg} \cdot \mathrm{kg}^{-1}$ orally. All continuous peripheral nerve blocks were performed under general anesthesia or intravenous sedation, and if necessary, the patient's airway was secured by tracheal intubation or laryngeal mask airway without neuromuscular blockade. The choice of regional anesthesia technique, the first bolus dose, and the mode of administration of local anesthetics were based on the anesthesiologist's preference. A sterile procedure was used to insert the CPNB catheter. The anesthesiologist wore a mask, cap, sterile gown, and gloves. The puncture site was prepared with a $10 \%$ povidone-iodine solution, and surrounding areas were covered with sterile drapes. All 
CPNBs were positioned using nerve stimulators for precise nerve location (Stimuplex ${ }^{\circledR}$ HNS, Braun, Melsungen, Germany), except for fascia iliaca compartment blocks. Insulated short-bevelled needles (MiniSet ${ }^{\circledR}$; Pajunk, Geisingen, Germany; or Contiplex ${ }^{\circledR}$; B. Braun, Melsungen, Germany) were connected to the nerve stimulator. Needle placement was judged correct when muscle contractions persisted at a current of $0.5 \mathrm{~mA}(100 \mu \mathrm{s}, 1 \mathrm{~Hz})$. If muscle contractions remained below $0.5 \mathrm{~mA}$, the needle was withdrawn to avoid possible intraneural injection. The nonstimulating catheter (MiniSet ${ }^{\circledR}$; Pajunk, Geisingen, Germany; or Contiplex ${ }^{\circledR}$; B. Braun, Melsungen, Germany) was then inserted from 2 to $5 \mathrm{~cm}$ and secured with adhesive strips and transparent occlusive dressing. After an aspiration test and an injection of $1 \%$ lidocaine $0.1 \mathrm{~mL} \cdot \mathrm{kg}^{-1}$ with epinephrine 1:200000 to exclude intravascular placement, the children received a bolus of local anesthetic solution $0.5-1 \mathrm{~mL} \cdot \mathrm{kg}^{-1}$ (maximum $25 \mathrm{~mL}$ based on the catheter location and the patient's weight) via the catheter injected over a 5-min period. When possible, the location of the catheter was verified radiologically with contrast dye $0.1 \mathrm{~mL} \cdot \mathrm{kg}^{-1}$ (Iopamidol ${ }^{\circledR} 200$, Shering Pharmaceutical, Lys-Lez-Lannoy, France). The study period evaluated all catheters inserted with nerve stimulation guidance and before the use of ultrasound guidance in our practice of regional techniques.

The postoperative infusion of local anesthetic, which was also based on catheter location and patient's weight, was administered at $0.1-0.2 \mathrm{~mL} \cdot \mathrm{kg}^{-1} \cdot \mathrm{hr}^{-1}$. If there were no contraindications with the first dose given at the end of surgery, the following non-steroidal anti-inflammatory drugs were administered as part of multimodal analgesia management: niflumic acid $40 \mathrm{mg} \cdot \mathrm{kg}^{-1} \mathrm{rec}-$ tally or ketoprofene $2 \mathrm{mg} \cdot \mathrm{kg}^{-1}$ iv twice daily and paracetamol $15 \mathrm{mg} \cdot \mathrm{kg}^{-1} i v$ or po four times daily. Pain scores for children $<7$ years old were evaluated by the Children and Infants Postoperative Pain Score (CHIPPS), and pain scores in older children were evaluated by the visual analog scale (VAS) ranging from $0=$ no pain to $10=$ worst imaginable pain. If pain control was considered insufficient (i.e., VAS or CHIPPS score $>3$ ), nalbuphine $0.2 \mathrm{mg} \cdot \mathrm{kg}^{-1}$ (four times daily), tramadol $0.5 \mathrm{mg} \cdot \mathrm{kg}^{-1}$ (four times daily), or intravenous patientcontrolled morphine analgesia were administered as rescue analgesics. If there was a premature discontinuation of local anesthetic infusion because the analgesia was deemed inadequate, the pain scores were recorded until the catheter was removed. At the end of the study period, child/parent satisfaction was recorded (unsatisfied, satisfied, very satisfied).

All adverse events were recorded during the CPNB period, including mechanical complications (i.e., premature discontinuation of local anesthetic infusion, catheter occlusion, catheter disconnection, local anesthetic leakage around catheter), hematoma, insensate extremity (numbness to paralysis), sensory blockade (hypoesthesia, dysesthesia), pruritus, nausea, vomiting, urinary retention, or signs of local anesthetic toxicity, local infection (redness, heat, edema, outflow), pus, cellulitis, fever (temperature $>38.5^{\circ} \mathrm{C}$ ), or shivering. If signs of local infection appeared with fever, the catheter was systematically removed and the distal tip was quantitatively cultured within 1 hour using a modified technique for intravascular catheters. ${ }^{10}$ Based on clinical need, the children were visited by nurses or an anesthesiologist twice daily or more frequently. Adverse events were compared by age group ( $<7$ years old and $\geq 7$ years old) and by function of catheter location.

\section{Statistical analysis}

A convenience sample of 292 patients is reported. An overall description of the recorded variables was performed. The quantitative values are expressed as average (SD), median (extremes), or number (percent). Continuous variables were compared with the Mann-Whitney $U$-test. Categorical variables were compared with the Chi square test. Using multiple logistic regression, the risk factors for adverse events were reported by odds ratio adjusted with $95 \%$ intervals. Statistical significance was accepted at $P<0.05$, and statistical analysis was performed using SAS $^{\circledR}$ software version 9 (SAS Institute, Cary, NC, USA) in the Medical Computer Programming Department of the University Hospital of Montpellier, France.

\section{Results}

Three hundred thirty-nine catheters were studied in 292 children. The median age of the children was $8 \mathrm{yr}$ (6 months to $17 \mathrm{yr}$ ); $44 \%$ of the children were age 1-6 yr and $56 \%$ were age 7-17 yr. The median weight was $28 \mathrm{~kg}$ (7-116 kg). Hip, femoral, or tibial osteotomies were reported in $44.5 \%$ of the patients. Six percent of the perineural catheters were indicated for analgesic procedures (traction of femoral shaft fracture, complex regional pain syndrome, or tumoral chronic pain). All demographic data and surgical indications are noted in Table 1. Six pediatric anesthesiologists placed 339 non-stimulating catheters.

\section{Catheter location and drugs}

Three hundred eight (90\%) lower limb and 31 (10\%) upper limb catheters were analyzed. Foot surgery (tibial osteotomies, club foot repair, and hallux valgus repair) was the main surgical procedure, and continuous popliteal nerve block was the most common location $(50.5 \%)$. Continuous psoas 
Table 1 Demographic data and surgical indications expressed as the median (extremes) or number of cases (percent)

\begin{tabular}{ll}
\hline Age (yr) & $8(0.6-17)$ \\
Age range (\%) & \\
$0-6$ yr & 43.73 \\
$7-17$ yr & 56.27 \\
Sex ratio (male/female) & $0.55 / 0.45$ \\
Weight (kg) & $28(7-116)$ \\
Catheter duration (hr) & $61.6(0-264)$ \\
Surgical indications, no. of cases (\%) & \\
Osteotomies & $151(44.5)$ \\
Club foot repair & $93(27.4)$ \\
Analgesia & $20(6)$ \\
Hallux valgus repair & $14(4.1)$ \\
Knee ligamentoplasty & $13(3.8)$ \\
Ankle arthrodesis & $9(2.7)$ \\
Plastic surgery & $7(2.1)$ \\
Others & $32(9.4)$ \\
\hline
\end{tabular}

compartment blocks were reported in $24 \%$ of the patients, femoral nerve blocks in $14.5 \%$, axillary block in $5 \%$, infraclavicular block in $5 \%$, and interscalene block in $1 \%$. Ninety-eight percent of the 245 catheters studied were correctly located on anteroposterior radiographs. The mean dose of local anesthetic bolus was $0.49 \pm 0.16 \mathrm{~mL} \cdot \mathrm{kg}^{-1}$ (bupivacaine $0.61-1.22 \mathrm{mg} \cdot \mathrm{kg}^{-1}$, or ropivacaine 0.49 $0.98 \mathrm{mg} \cdot \mathrm{kg}^{-1}$ ), and the mean dose of local anesthetic infusion was $0.11 \pm 0.04 \mathrm{~mL} \cdot \mathrm{kg}^{-1} \cdot \mathrm{hr}^{-1}$ (bupivacaine $0.14-0.28 \mathrm{mg} \cdot \mathrm{kg}^{-1} \cdot \mathrm{hr}^{-1}$, or ropivacaine $0.11-0.22$ $\left.\mathrm{mg} \cdot \mathrm{kg}^{-1} \cdot \mathrm{hr}^{-1}\right)$. The median duration of CPNB was $61.6 \mathrm{hr}(0-264 \mathrm{hr})$. During the first two years of the study, $0.125 \%$ or $0.25 \%$ bupivacaine was used preferentially in the bolus dose and the continuous infusion. From 2004 to $2007,0.1 \%$ or $0.2 \%$ mainly ropivacaine was used $(100 \%$ of local anesthetic infusions since December 2005). For the induction dose, clonidine $1 \cdot \mu \mathrm{g} \cdot \mathrm{kg}^{-1}$ was used as an adjuvant in $46 \%$ of the patients.

\section{Efficacy of CPNB and satisfaction}

In the postoperative period, $93 \%$ of the children were given paracetamol and $89 \%$ were given non-steroidal antiinflammatory drugs. Sixty percent of the patients needed at least one rescue dose of analgesia. Nalbuphine was used most frequently as rescue analgesia (75\% of cases). The cumulated mean dose of nalbuphine was $0.23 \mathrm{mg} \cdot \mathrm{kg}^{-1}$ during the study period. Tramadol was used in $22 \%$ of patients and PCA morphine in 3\%. Postoperative pain relief was excellent in the majority of patients during the first $48 \mathrm{hr}$ postoperatively (Fig. 1a, b). The median pain score was 0 throughout the study period in the two age
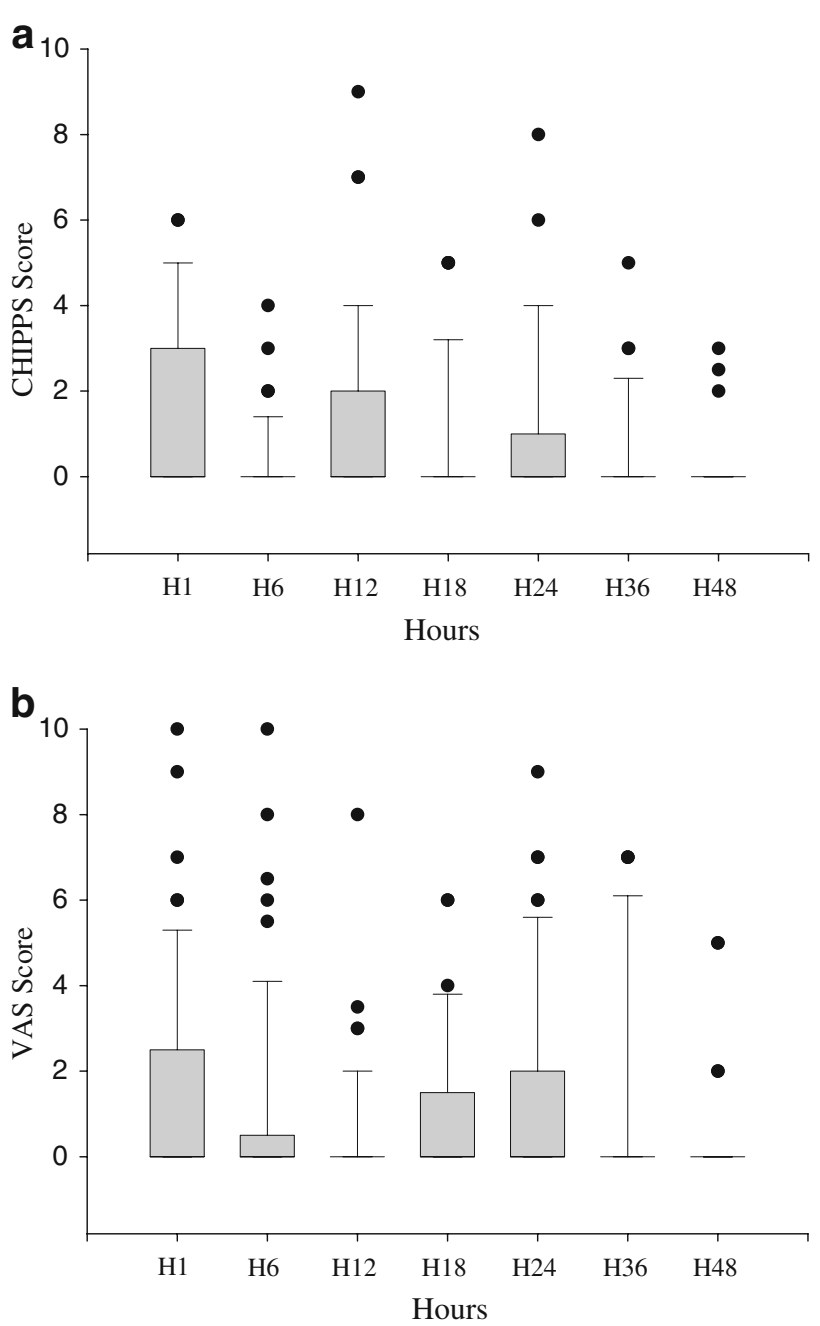

Fig. 1 a Children and Infants Postoperative Pain Scale (CHIPPS) scores in the youngest children $(6 \mathrm{mth}$ to $6 \mathrm{yr})$ during the first postoperative $48 \mathrm{hr}$. The box represents the 25 th to 75 th percentiles; the dark line is the median. The extended bars represent the 10th to 90th percentiles, and the dark circles represent values outside this range. The median pain score was zero during the first $48 \mathrm{hr}$ postoperatively. b VAS scores in the oldest children (7-17 yr) during the first $48 \mathrm{hr}$ postoperatively. The box represents the 25th to 75 th percentiles; the dark line represents the median. The extended bars represent the 10th to 90th percentiles, and the dark circles represent values outside this range. Note that the median pain score was zero during the first $48 \mathrm{hr}$ postoperatively

groups. Eighty-eight percent of children or parents were very satisfied, $11 \%$ satisfied, and $1 \%$ unsatisfied.

\section{Adverse events during CPNB}

Two hundred eleven adverse events were noted in 153 CPNBs (45.1\%). The most frequently reported adverse events were mechanical problems $(n=68 ; 20.1 \%)$ dominated by leakage of local anesthetic around the catheter and catheter dislodgment. The other most common minor 
Table 2 Adverse events by catheter location among the total adverse events $(n=211)$

\begin{tabular}{|c|c|c|c|c|c|c|c|c|}
\hline & $\begin{array}{l}\text { Mechanical } \\
\text { complications }\end{array}$ & PONV & $\begin{array}{l}\text { Urinary } \\
\text { retention }\end{array}$ & Pruritus & $\begin{array}{l}\text { Persistent } \\
\text { motor } \\
\text { block }\end{array}$ & Paresthesia & $\begin{array}{l}\text { Inflammatory } \\
\text { local signs }\end{array}$ & $\begin{array}{l}\text { Adverse } \\
\text { events (\%) }\end{array}$ \\
\hline Axillary & 6 & 4 & 0 & 0 & 6 & 2 & 0 & $18(8.5)$ \\
\hline Infraclavicular & 7 & 1 & 0 & 0 & 2 & 3 & 1 & $14(6.6)$ \\
\hline Interscalene & 0 & 1 & 0 & 0 & 0 & 1 & 0 & $2(0.9)$ \\
\hline Femoral & 14 & 5 & 2 & 1 & 2 & 3 & 0 & $27(12.8)$ \\
\hline PCB & 17 & $24 *$ & 1 & 2 & 2 & 2 & 0 & $48(22.8)$ \\
\hline Popliteal & 24 & 15 & 2 & 0 & $49 *$ & 11 & 1 & $102(48.4)$ \\
\hline Total, $n(\%)$ & $68(32.2)$ & $50(23.8)$ & $5(2.4)$ & $3(1.4)$ & $61(28.9)$ & $22(10.4)$ & $2(0.9)$ & $211(100)$ \\
\hline
\end{tabular}

$P C B$ psoas compartment block; $P O N V$ postoperative nausea and vomiting

$* P<0.05$

adverse event was nausea/vomiting $(n=50,14.7 \%)$. We noted a low incidence of urinary retention $(1.5 \%)$ and pruritus $(0.9 \%)$. No patient presented signs of local anesthetic systemic toxicity. Persistent motor blockade occurred in $18 \%(n=61)$ of cases and resolved spontaneously with decrease or discontinuation of local anesthetic infusion. Paresthesiae were reported in $22(6.5 \%)$ children. All paresthesiae disappeared at the end of the local anesthetic continuous infusion. Adverse events are reported in Table 2. Two patients presented local inflammatory signs with fever (one child at $24 \mathrm{hr}$ and another child at $48 \mathrm{hr}$ ). Bacterial culture of the catheter was negative in both cases. Premature discontinuation of local anesthetic infusion occurred in 52 CPNBs (15.3\%). The discontinuations were due to accidental catheter withdrawals $(40.5 \%)$, persistent motor block $(7.7 \%)$, catheter occlusion $(3.8 \%)$, and pain relief failure (3.8\%) (Table 3). In two cases, the surgeon had requested removal of the catheter to explore a hypothetic compartment syndrome after tibial shaft osteotomy.

Table 3 Reasons for premature discontinuation of local anesthesia infusion

\begin{tabular}{lrr}
\hline & $n$ & $\%$ \\
\hline Accidental catheter withdrawal & 21 & 40.5 \\
Inadequate analgesia & 7 & 13.5 \\
Catheter dislodgement & 5 & 9.7 \\
Persistent motor block & 4 & 7.7 \\
Leakage at catheter site & 4 & 7.7 \\
Catheter occlusion & 2 & 3.8 \\
Pain relief failure & 2 & 3.8 \\
Surgeon request & 2 & 3.8 \\
No intravenous access & 2 & 3.8 \\
Inflammatory local signs & 2 & 3.8 \\
Not identified & 1 & 1.9 \\
Total & 52 & 100 \\
\hline
\end{tabular}

We noted no significant difference for adverse events between age groups. The logistic regression analysis identified nausea/vomiting to be associated with continuous psoas compartment block $\left(\mathrm{OR}_{\text {adjusted }}=3.42,95 \% \mathrm{CI}\right.$ [1.71-6.84]) and persistent insensate extremity with continuous popliteal nerve block $\left(\mathrm{OR}_{\text {adjusted }}=5.08,95 \% \mathrm{CI}\right.$ [2.02-12.81]) (Table 2).

\section{Discussion}

We report that using CPNB in a large pediatric population at a tertiary care teaching hospital using standardized insertion techniques is associated with very good quality postoperative analgesia, high child/parent satisfaction, and no serious adverse events in the postoperative period.

Technical characteristics of CPNB in children

CPNB allows effective and prolonged postoperative pain relief in pediatric orthopedic patients. We report a mean infused dose of $0.11 \mathrm{~mL} \cdot \mathrm{kg}^{-1} \cdot \mathrm{hr}^{-1}$ in our pediatric patients. These results are similar to those reported in the literature. The suggested dose for continuous infusion via a perineural catheter ranged from $0.1^{4,5,11}$ to $0.2 \mathrm{~mL} \cdot \mathrm{kg}^{-1}$. $\mathrm{hr}^{-1} \cdot{ }^{12,13}$ The recommended first bolus dose is approximately $0.5 \mathrm{~mL} \cdot \mathrm{kg}^{-1} \cdot 4,5,11$

The median duration of CPNB was $61.6 \mathrm{hr}$ (range 0-264 hr). Between postoperative days 2 and 3, the anesthesiologists who were responsible for the patients evaluated the point at which postoperative pain was bearable without nerve block. In patients with a complex regional pain syndrome, the catheter was maintained longer than $72 \mathrm{hr}$. One catheter was maintained for 11 days for cancer pain management.

Bupivacaine was used exclusively in continuous infusion during the first year of the study, but ropivacaine has 
gradually become the optimal choice in our daily practice. ${ }^{14,15}$ Nowadays, ropivacaine is currently used in $100 \%$ of our CPNBs. We consider that $0.2 \%$ ropivacaine permits a differential neural block avoiding motor blockade. ${ }^{16}$

\section{Quality of postoperative analgesia}

In adults, CPNB has demonstrated its superiority in postoperative pain management. The analysis of pain scores shows effective management of postoperative pain relief in children with CPNB. Postoperative analgesia was excellent. As demonstrated in other studies, ${ }^{4-6,11}$ CPNB provided a high level of satisfaction in postoperative pain management in our pediatric patients. Nevertheless, we did not compare CPNB with other methods of postoperative analgesia. It is impossible to demonstrate any superiority of CPNB in terms of postoperative analgesia. In our study, $60 \%$ of children needed at least one rescue analgesic injection. The cumulated mean dose of nalbuphine was $0.23 \mathrm{mg} \cdot \mathrm{kg}^{-1}$, i.e., one injection of nalbuphine per pediatric patient throughout the study period. Forty percent of the first injections of rescue analgesic were given in the recovery room. These results are similar to those reported for adult and pediatric orthopedic patients receiving CPNB in the postoperative period. ${ }^{6,7,17}$ In a similar study, Ganesh et al. ${ }^{6}$ noted that $56 \%$ of children required an opioid within the first $8 \mathrm{hr}$ after surgery. These results are higher than those reported in adults. The use of dilute concentrations of local anesthetics in order to avoid motor blockade in the postoperative period may explain this increased need for rescue analgesics. A few children had high pain scores due to inadequate analgesia in nerve territories involved in the surgical procedure. Moreover, some catheters that were efficient during the surgical procedure failed to work in the first postoperative hours due to misplacement by secondary migration. Another interesting result is the relatively high percentage use of rescue analgesics in the recovery room despite the quality of the postoperative pain relief. This use may be due to residual tourniquet pain, incomplete sensory recovery after peripheral nerve block, emergence delirium secondary to intraoperative sevoflurane use, child's anxiety due to lack of a parent, or inappropriate use of nalbuphine as a sedative effect.

\section{Adverse events}

Mechanical problems (premature discontinuation of local anesthetic infusion, catheter occlusion, catheter disconnection, local anesthetic leakage around catheter) represented $32 \%$ of all minor side effects noted. Similarly, Klein et al. ${ }^{18,19}$ observed technical difficulties with continuous interscalene block in $9-44 \%$ of adult cases. Recently, Capdevila et $a l .{ }^{7}$ noted technical problems due to catheters and devices in approximately $18 \%$ of CPNBs. The incidence of urinary retention and pruritus was very low in our pediatric population. CPNB avoids the use of opiates in the postoperative period, and thus decreases their related side effects. ${ }^{20}$ Sixty-one patients presented with a persistent insensate extremity and 22 had paresthesia or dysesthesia during the postoperative period. Persistent insensate extremity was significantly associated with continuous popliteal nerve block. This could be explained by the anatomic relationship of the perineural space and the target nerve/plexus in this location. Ilfeld et al. ${ }^{21}$ reported a significant role played by local anesthetic volume and concentration in perineural infusion in a relatively confined perineural space, such as the popliteal sciatic nerve location. Ilfeld et al. reported that $0.2 \%$ ropivacaine infusion at $8 \mathrm{~mL} \cdot \mathrm{hr}^{-1}$ caused significantly more insensate extremity than $0.4 \%$ ropivacaine infusion at $4 \mathrm{~mL} \cdot \mathrm{hr}^{-1}$. Based on this possibility, the incidence of insensate extremity, especially during continuous popliteal sciatic block, may be related to an excessively high basal infusion rate in our pediatric population. On the other hand, these side effects appeared mainly in the first two years of the study period when we used $0.25 \%$ bupivacaine postoperatively. Compared with bupivacaine, ropivacaine may facilitate a more precise differential blockade. ${ }^{16}$

In our study, we observed a low rate (14.6\%) of postoperative nausea and vomiting (PONV). The incidence of PONV in our trial is similar to the results noted by Ganesh et al. (14\%). ${ }^{6}$ The results of these two studies are lower than those of continuous pediatric epidural analgesia trials, which reported an incidence of PONV from 22 to $40 \% .^{22-24}$ The authors claimed that nausea and vomiting were related to epidural opioid use. In a retrospective study, Jilly et al. ${ }^{25}$ reported a lower incidence of nausea and vomiting in continuous epidural infusion excluding opioids. With the exception of nausea and vomiting episodes directly related to surgical procedures, ${ }^{26}$ the low incidence noted in our study was probably related to the limitation of opioid use. In our study population, PONV was more frequently associated with continuous psoas compartment block relative to the use of rescue analgesia in major hip surgery.

Sepsis was suspected in two patients. Local inflammatory signs with fever prompted the removal of the catheter. Nevertheless, bacterial culture of the catheter tip was negative in both cases and the fever disappeared spontaneously. In a study in adults, Capdevila et l. $^{7}$ reported positive bacterial colonization in $28 \%$ of perineural catheters. Fortunately, the reported incidence of local inflammatory signs was only $3 \%$. Cuvillon et ll $^{27}$ prospectively reported an incidence of $57 \%$ of colonized femoral catheters and only $1.5 \%$ of bacteremia. Similarly, the risk of epidural infection is low in the pediatric population undergoing short-term perioperative treatment. ${ }^{1,28}$ From 348 continuous epidural catheters in children, Lejus 
et $a l .{ }^{29}$ reported 11 cases with the associated general signs of fever. The bacterial cultures of the catheters were always negative.

Premature discontinuation of CPNB due to catheter failure occurred in $15 \%$ of cases. The most common reason was accidental catheter removal by the children. Ganesh et al. ${ }^{6}$ noted a similar incidence of catheter failure (15\%). The rate of premature discontinuation is lower than that reported for epidurals. Wood et al..$^{22}$ reported premature discontinuation of epidural infusions in 41 cases among 190 epidurals (21.5\%), mainly due to technical problems. Jylli et al. ${ }^{25}$ reported that $37 \%$ of epidural infusions were discontinued prematurely, primarily related to catheter dislodgement or leakage. In a previous study in pediatric orthopedic patients, we found the premature discontinuation of regional analgesia technique more frequent with continuous epidurals than with CPNB. ${ }^{5}$

\section{Study limitations}

The procedures, the first bolus dose, the mode of administration of local anesthetic, and the type and concentration of local anesthetics were not standardized but were based on the anesthesiologist's preference. This is probably important for the reported evaluation of motor blockade and for some adverse events. There was no active comparator group to evaluate the quality of these pain management techniques in children relative to other methods. Furthermore, we did not collect pain scores during movement, and the pain scores presented in Fig. 1 probably underestimated the maximal pain scores of our patients. Finally, our orthopedic surgeons are specialized in lower limb surgery. Thus, we performed more continuous peripheral lower limb blocks than upper limb blocks. This could have biased our conclusions about the incidence and the type of adverse events. Furthermore, the sample size of our study was not large enough to prove that serious complications cannot occur. A final limitation is that the study did not consider the use of ultrasound-guided techniques for needle and catheter insertion.

In conclusion, this study ably demonstrates the efficacy and feasibility of CPNB in children undergoing major orthopedic surgery. CPNB promoted prolonged analgesia in the majority of patients and favourable child/parent satisfaction profiles with only minor adverse events.

\section{Competing interests None declared.}

\section{References}

1. Giaufre E, Dalens B, Gombert A. Epidemiology and morbidity of regional anesthesia in children: a one-year prospective survey of the French-Language Society of Pediatric Anesthesiologists. Anesth Analg 1996; 83: 904-12.

2. Rochette A, Dadure C, Raux O, Troncin R, Mailhee P, Capdevila $X$. A review of pediatric regional anesthesia practice during a 17-year period in a single institution. Paediatr Anaesth 2007; 17:874-80.

3. Tobias JD, Mencio GA. Popliteal fossa block for postoperative analgesia after foot surgery in infants and children. J Pediatr Orthop 1999; 19: 511-4.

4. Dadure $C$, Pirat P, Raux $O$, et al. Perioperative continuous peripheral nerve blocks with disposable infusion pumps in children: a prospective descriptive study. Anesth Analg 2003; 97 : 687-90.

5. Dadure C, Bringuier S, Nicolas F, et al. Continuous epidural block versus continuous popliteal nerve block for postoperative pain relief after major podiatric surgery in children: a prospective comparative randomized study. Anesth Analg 2006; 102: 744-9.

6. Ganesh A, Rose JB, Wells L, et al. Continuous peripheral nerve blockade for inpatient and outpatient postoperative analgesia in children. Anesth Analg 2007; 105: 1234-42.

7. Capdevila $X$, Pirat $P$, Bringuier $S$, et al. Continuous peripheral nerve blocks in hospital wards after orthopedic surgery: a multicenter prospective analysis of the quality of postoperative analgesia and complications in 1,416 patients. Anesthesiology 2005; 103: 1035-45.

8. Neuburger M, Buttner J, Blumenthal S, Breitbarth J, Borgeat A. Inflammation and infection complications of 2285 perineural catheters: a prospective study. Acta Anaesthesiol Scand 2007; 51: $108-14$.

9. Buttner W, Finke W. Analysis of behavioural and physiological parameters for the assessment of postoperative analgesic demand in newborns, infants and young children: a comprehensive report on seven consecutive studies. Paediatr Anaesth 2000; 10: 303-18.

10. Brun-Buisson C, Abrouk F, Legrand P, Huet Y, Larabi S, Rapin $M$. Diagnosis of central venous catheter-related sepsis. Critical level of quantitative tip cultures. Arch Intern Med 1987; 147: 873-7.

11. Duflo F, Sautou-Miranda V, Pouyau A, et al. Efficacy and plasma levels of ropivacaine for children: controlled regional anaesthesia following lower limb surgery. Br J Anaesth 2006; 97: 250-4.

12. Sciard D, Matuszczak M, Gebhard R, Greger J, Al-Samsam T, Chelly JE. Continuous posterior lumbar plexus block for acute postoperative pain control in young children. Anesthesiology 2001; 95: 1521-3.

13. Ivani $G$, Codipietro L, Gagliardi F, Rosso F, Mossetti V, Vitale P. A long-term continuous infusion via a sciatic catheter in a 3-yearold boy. Paediatr Anaesth 2003; 13: 718-21.

14. Mazoit JX, Dalens BJ. Ropivacaine in infants and children. Curr Opin Anaesthesiol 2003; 16: 305-7.

15. Ivani $G$. Ropivacaine: is it time for children? (Editorial). Paediatr Anaesth 2002; 12: 383-7.

16. McClure JH. Ropivacaine. Br J Anaesth 1996; 76: 300-7.

17. Grant SA, Nielsen KC, Greengrass RA, Steele SM, Klein SM. Continuous peripheral nerve block for ambulatory surgery. Reg Anesth Pain Med 2001; 26: 209-14.

18. Klein SM, Grant SA, Greengrass RA, et al. Interscalene brachial plexus block with a continuous catheter insertion system and a disposable infusion pump. Anesth Analg 2000; 91: 1473-8.

19. Klein SM, Steele SM, Nielsen KC, et al. The difficulties of ambulatory interscalene and intra-articular infusions for rotator cuff surgery: a preliminary report. Can J Anesth 2003; 50: 265-9.

20. Lloyd-Thomas AR. Pain management in paediatric patients. Br J Anaesth 1990; 64: 85-104.

21. Ilfeld BM, Loland VJ, Gerancher JC, et al. The effects of varying local anesthetic concentration and volume on continuous 
popliteal sciatic nerve blocks: a dual-center, randomized, controlled study. Anesth Analg 2008; 107: 701-7.

22. Wood CE, Goresky GV, Klassen KA, Kuwahara B, Neil SG. Complications of continuous epidural infusions for postoperative analgesia in children. Can J Anaesth 1994; 41: 613-20.

23. Dalens B, Tanguy A, Haberer JP. Lumbar epidural anesthesia for operative and postoperative pain relief in infants and young children. Anesth Analg 1986; 65: 1069-73.

24. Ecoffey C, Dubousset AM, Samii K. Lumbar and thoracic epidural anesthesia for urologic and upper abdominal surgery in infants and children. Anesthesiology 1986; 65: 87-90.

25. Jylli L, Lundeberg S, Olsson GL. Retrospective evaluation of continuous epidural infusion for postoperative pain in children. Acta Anaesthesiol Scand 2002; 46: 654-9.
26. Karlsson E, Larsson LE, Nilsson K. Postanaesthetic nausea in children. Acta Anaesthesiol Scand 1990; 34: 515-8.

27. Cuvillon P, Ripart J, Lalourcey L, et al. The continuous femoral nerve block catheter for postoperative analgesia: bacterial colonization, infectious rate and adverse effects. Anesth Analg 2001; 93: 1045-9.

28. Strafford MA, Wilder RT, Berde $C B$. The risk of infection from epidural analgesia in children a review of 1620 cases. Anesth Analg 1995; 80: 234-8.

29. Lejus C, Surbled M, Schwoerer D, et al. Postoperative epidural analgesia with bupivacaine and fentanyl: hourly pain assessment in 348 paediatric cases. Paediatr Anaesth 2001; 11: 327-32. 